\title{
CORRESPONDENCE
}

\section{ADVISORY COMMITTEE ON THE WELFARE OF THE BLIND.}

To the Editors of THE British Journal OF OPHThalmology.

DEAR SIRS,-I have read the article in the December, 1945 copy of the British Journal of Ophthalmology headed Memorandum on the Notification and Certification of the Blind. The figures quoted are those for the year 1942 and I enclose a copy of the latest statistics (1945) for the information of the writer of the article.

In paragraph 2 of the article there is a reference to the definition of blindness for school children, viz., "too blind to be able to read the ordinary school books used by children." This definition has been replaced by the following; "blind pupils, that is to say, pupils who have no sight, and whose sight is, or is likely to become so defective that they require education by methods not involving the use of sight." This new definition is contained in Statutory Rules and Orders, 1945 , No. 1076.

I do not quite understand the figures for the L.C.C. mentioned on page 658 , the total certified plus the number rejected for the period 1935 to 1943 come to 8953 , whereas it is stated that the total is 10917 .

With reference to the statement on page 660 that there are many "old people who are not registered as blind because they are receiving Old Age Pensions already." If the pension is noncontributory and the persons are under 70 , they would normally not be granted a Pension unless they are registered blind persons. If they are over 70 or are in receipt of contributory old age pensions, they would not, if blind, receive supplementary pensions. The Assistance Board are precluded from paying supplementary pensions to old age pensioners who are blind, and a considerable number of applicants for supplementary pensions are passed each year by the Assistance Board to the Blind Persons Authority for certification and registration as blind persons.

\section{Yours faithfully,}

F. R. BARnes, Secretary.

MINISTRY OF HEALTH,

WHITEHALL, LONDON, S.W.1

May 30th, 1946 


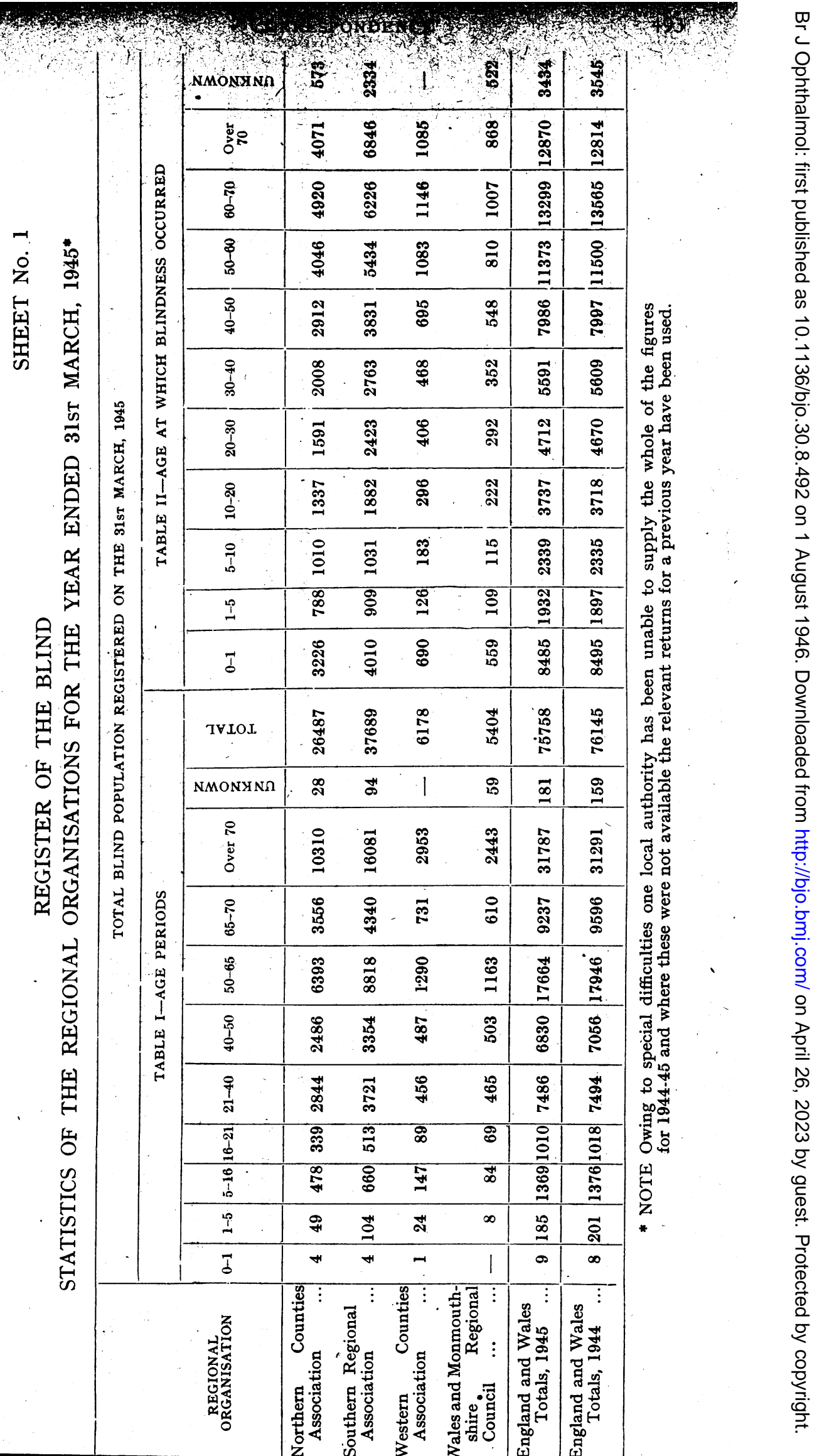




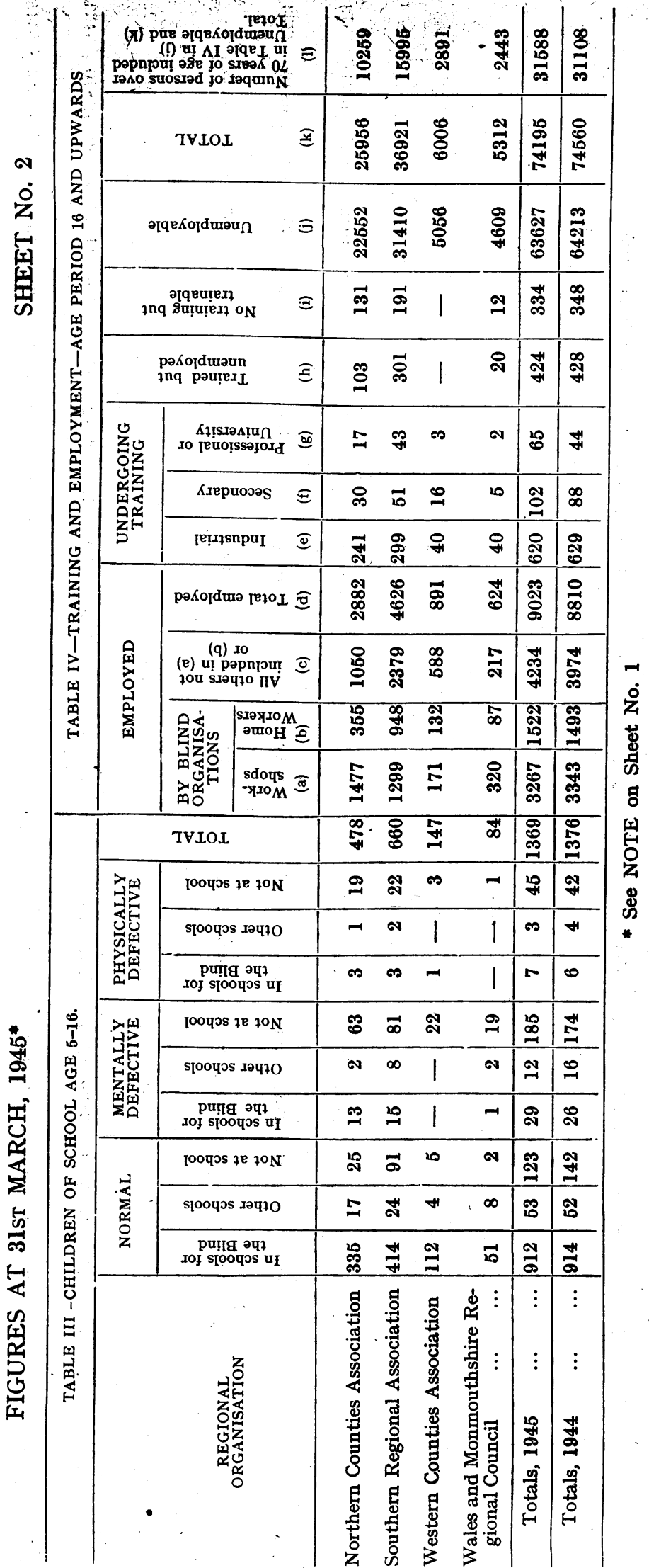




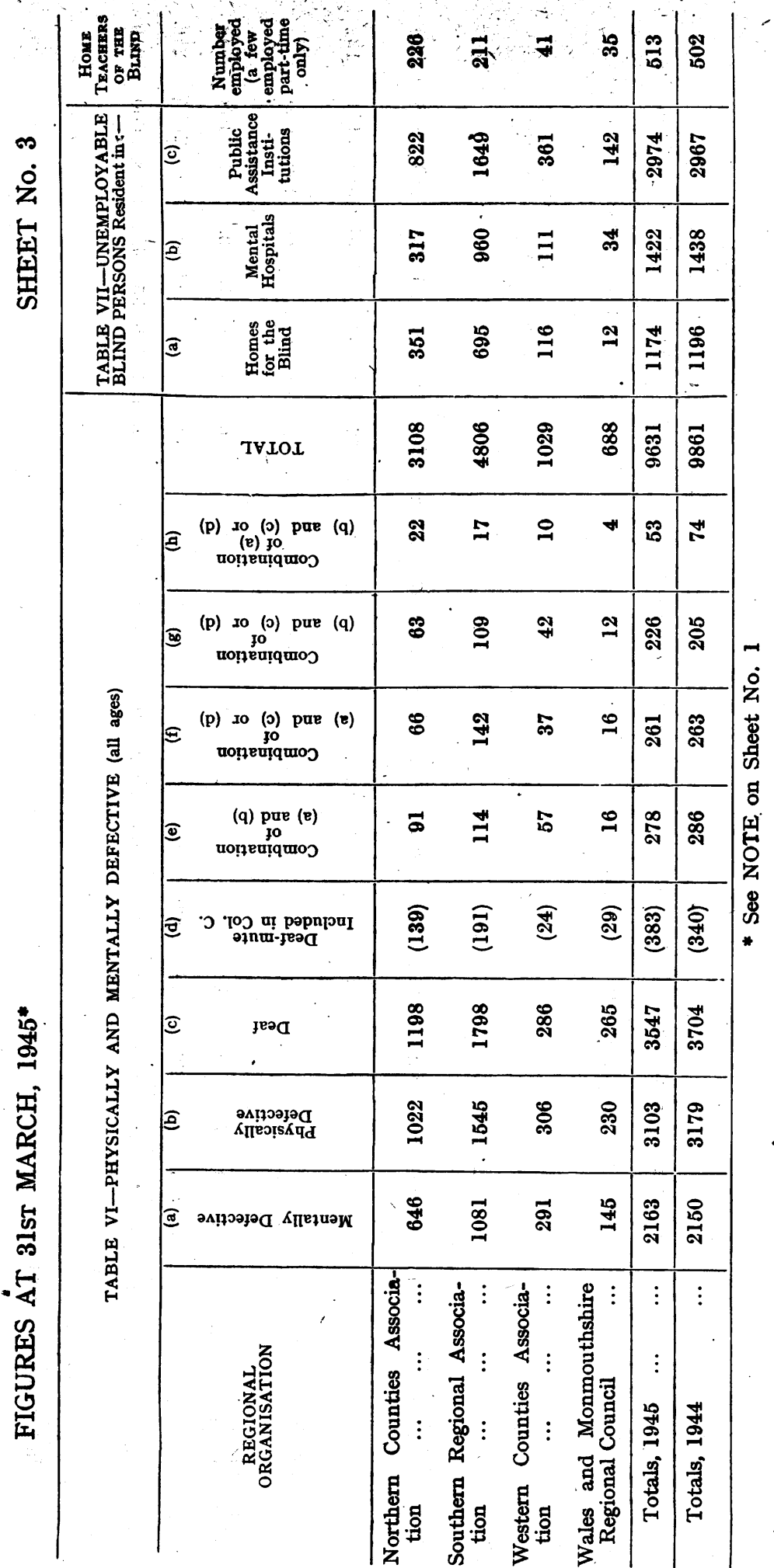




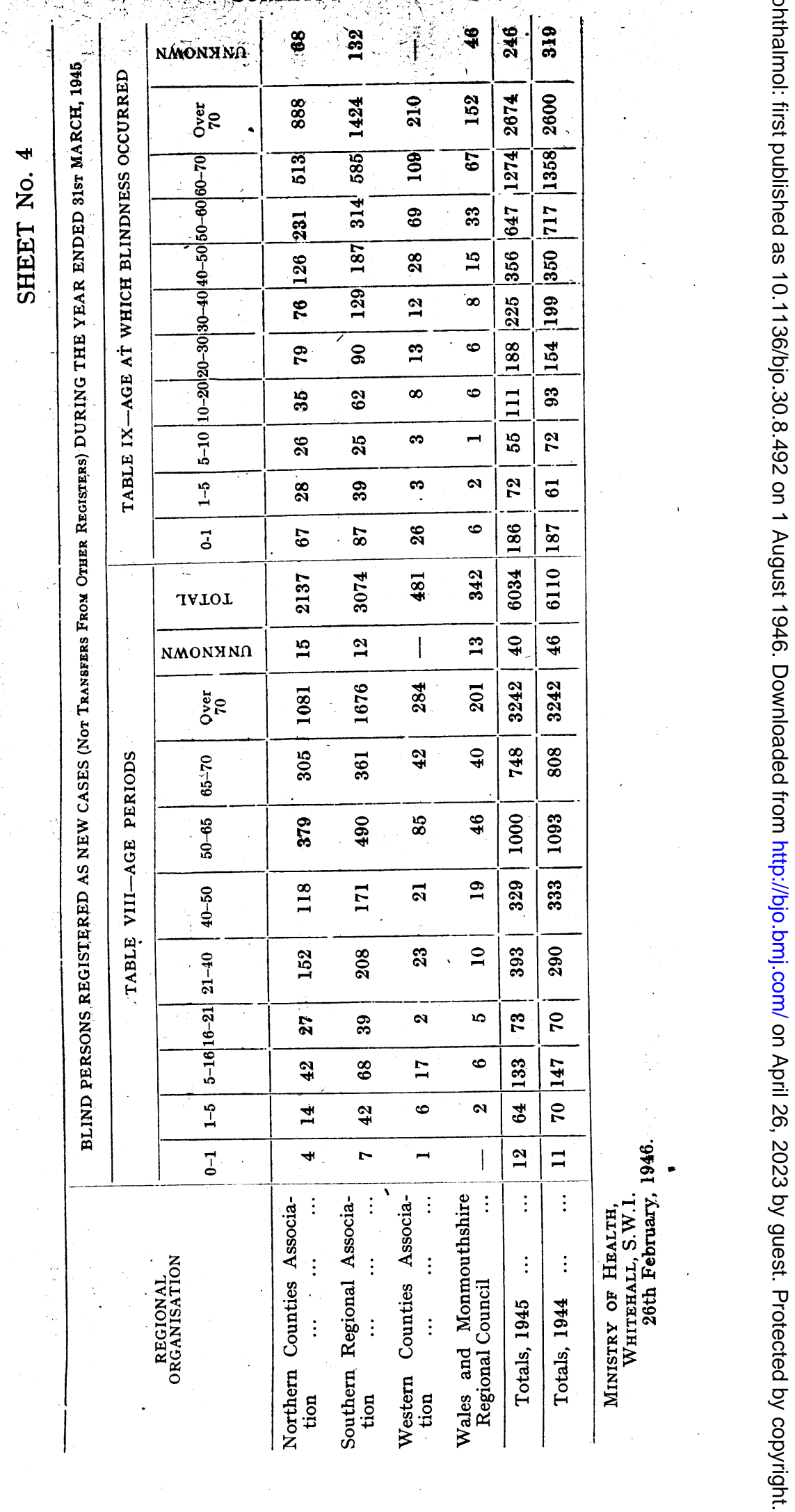

